\title{
Cerro Pelado: la construcción de la identidad a través de las
}

\author{
festividades.
}

\section{Cerro Pelado: a construção da identidade através de festividades}

\author{
Cerro Pelado: the construction of identity through festivities
}

\author{
Alejandro Gau de Mello ${ }^{1}$ \\ Eugenia Antonella Liendo da Silva ${ }^{2}$ \\ Maria Victoria Manzoni Fagúndez ${ }^{3}$
}

\begin{abstract}
Resumen
El presente trabajo "Cerro Pelado: la construcción de la identidad a través de las festividades" fue realizado por estudiantes que integran la Asociación Civil Equipo Multidisciplinario en Estudios de Frontera. Dicha asociación tiene como misión recopilar e interpretar elementos que conforman la memoria local y la tradición de la frontera, como elementos axiales en el proceso de formación de los estudiantes y egresados de formación docente. Por lo tanto, se aspira como docentes a fomentar la producción de conocimiento académico. En el siguiente trabajo de investigación tiene como objetivo analizar la identidad de Cerro Pelado, este es una comunidad del departamento de Rivera que se ubica en el kilómetro 73 de la ruta 27. A partir de las festividades de dicho pueblo se pretende identificar en los pobladores el sentido de pertenencia, la identidad y cómo se van construyendo a lo largo del tiempo, desde su fundación (en el año 1964) hasta la actualidad. Dentro de las festividades que allí se realiza se pueden destacar principalmente dos que han permanecido en el tiempo, las criollas del 25 de agosto (Fecha Patria en el Uruguay), y día de la comunidad que lo celebran el día 29 de septiembre de cada año. Luego existen otras celebraciones que fueron surgiendo y otras que no son de tal relevancia para esta comunidad, que son los bailes, fiestas de las quinceañeras, casamiento colectivo, fiesta de la tradición, despedida a los estudiantes que egresan del liceo comunitario, primero de mayo y el día del peón rural.
\end{abstract}

Palabras claves: Comunidad; Festividades; Identidad; Memoria; Tradición

\section{Resumo}

O presente trabalho "Cerro Pelado: a construção da identidade através das festividades" foi realizado por alunos que integram a Equipe Multidisciplinar da Associação Civil em Estudos Fronteiriços. A missão desta associação é coletar e interpretar elementos que compõem a memória local e a tradição da fronteira, como elementos axiais no processo de formação de alunos e egressos da formação de professores. Por isso, eles aspiram como professores para incentivar a produção de conhecimento acadêmico. A presente pesquisa é analisar a identidade de Cerro Pelado, esta é uma comunidade no departamento de Rivera está localizado no quilômetro 73 da Rota 27. A partir das festividades desta cidade que é identificar as pessoas o sentido de pertença, a identidade e como eles são construídos ao longo do tempo, desde a sua fundação (em 1964) até o presente. Entre as festividades realizadas destacam-se duas que se mantiveram no tempo, as crioulas de 25 de agosto (data pátria no Uruguai), e dia de comunidade que comemoram em 29 de setembro de cada ano. Depois, há outras celebrações que foram surgindo e outros que não são de tal importância para esta comunidade, que são as danças, festas quinceaneras, festa de casamento tradição coletiva, estudantes de licenciatura que se formam a partir de comunidade Lyceum, mayday e o dia do trabalhador rural.

1 Profesor, Magister; Centro Latinoamericano de Economía Humana; Rivera, Uruguay, alejandrogaudemello@gmail.com

${ }^{2}$ Docente egresada en educación media; Centro Regional de Profesores del Norte, Tacuarembó, Departamento de Tacuarembó, Uruguay; eugeliendo95@gmail.com

${ }^{3}$ Docente egresada en educación media; Centro Regional de Profesores del Norte, Tacuarembó, Departamento de Tacuarembó, Uruguay; mativicky.2@gmail.com 


\section{Summary}

The present work "Cerro Pelado: the construction of the identity through the festivities" was carried out by students that integrate the Civil Association Multidisciplinary Team in Border Studies. The mission of this association is to collect and interpret elements that make up the local memory and the tradition of the border, as axial elements in the process of training students and graduates of teacher training. Therefore, they aspire as teachers to encourage the production of academic knowledge. In the following research work aims to analyze the identity of Cerro Pelado, this is a community of the department of Rivera that is located at kilometer 73 of the route 27 . From the festivities of said town is intended to identify the villagers the sense of belonging, the identity and how they are built over time, from its foundation (in 1964) to the present. Among the festivities held there can be highlighted two that have remained in time, the criollas of August 25 (Date Homeland in Uruguay), and community day that celebrate on September 29 of each year. Then there are other celebrations that were emerging and others that are not of such relevance to this community, which are the dances, parties quinceañeras, collective marriage, feast of tradition, farewell to students who graduate from the community high school, May first and the day of the rural laborer.

Keywords: Community; Festivities; Identity; Memory; Tradition

\section{Introducción}

De acuerdo a esta investigación se tiene como finalidad principal analizar cómo la comunidad de Cerro Pelado construye su identidad, teniendo como principal objeto de estudio las festividades. Para ello este trabajo cuenta con dos años (2017 y 2018) de trabajo de campo, partiendo desde una primera observación de la comunidad a una intervención, desde generar eventos donde se confraternizó con la comunidad hasta aplicar las técnicas de recolección de datos, principalmente las entrevistas; se trata por tanto de un trabajo de corte cualitativo, donde se recata principalmente la historia oral.

En lo que respecta a historia oral, es importante destacar que al tener la investigación un camino cualitativo el trabajo se enriquece y deja visualizar aún más la esencia, las cualidades, las costumbres pueden llegar a ser percibidas en lo material, pero aún más perduran en lo inmaterial, en el interior de la comunidad, lo más íntimo, hasta lo más superficial. Lo que implica un desafío extra de los investigadores a la hora de adentrarse en la comunidad y conocer sus gestos, lo vivido, su historia, su sentir, las imágenes, las emociones, los espacios, sus recuerdos y los olvidos, entre otras tantas más que se desarrollarán en dicho artículo.

En el desarrollo de este trabajo se destaca la historia fundacional de esta comunidad, la cual es la que constituye su cultura y su identidad, que la hace particular dentro del medio en la cual se ubica geográficamente. En lo que respecta a su identidad, cultura y principalmente el sentido de pertenencia de los pobladores de Cerro Pelado, cabe destacar que se pudo percibir a través de la festividades, allí estas tienen un papel importante ya que están presentes desde sus comienzos como comunidad, las fiestas son utilizadas como puente para que las tradiciones del lugar perduren, por ello en el artículo se hace hincapié en ellas 
desde la memoria colectiva, los recuerdos, el olvido y el relato histórico que está muy arraigado en el pueblito.

Además al adentrarse a lo que implicaba las celebraciones dentro de la comunidad, se puedo notar que papel que cumple la mujer dentro de la misma, ya sea en las propias fiestas como en la comunidad en sí. Se notó que tiene un rol importante, que allí se sienten a gusto, se ha ganado un espacio que es valorado por la comunidad y reconocen sus actividades, un claro ejemplo es su proyecto artesanal "Arte y Mania" y el grupo de zumba, que son dos emprendimientos reconocidos por los eventos a los cuales participan activamente.

\section{Hallazgos}

Para comenzar es importante destacar que Cerro Pelado es una comunidad rural, que se encuentra en el departamento de Rivera-Uruguay, además se ubica por la ruta 27 , en el kilómetro 73 limitando con varias localidades de la zona con las que mantiene una relación económica y sociocultural desde las festividades que comparten hasta el servicio escolar y liceal.

Dicha comunidad, según el entrevistado L.P surge en primera instancia como pueblo Zegarra, porque se empieza a conformar en tierras pertenecientes a esta firma. “(...) en 60, 70 años atrás era, Zegarra era una firma que tenía muy grande, tenía todo acá mirá, tenía allí en San Juan, tenía ahí donde está los Terra y nosotros acá donde está todo el establecimiento y va allá a lo de Tomacito (..) Se componía de treinta mil hectáreas"(Entrevistado: L.P, 2017). Luego a mediados del siglo XX, aproximadamente en el año 1964 se puede decir que adquiere el nombre de Cerro Pelado debido a las características geográficas del lugar, además es en este año se conforma el grupo "El Fogón” con su líder Tomás Berrutti, “Tomacito” para los habitantes del mismo, ya que su padre Plinio Berrutti es el que dona los terrenos (56 hectáreas aproximadamente) para que allí se establezca dicha población.

Con la donación de los terrenos este grupo "El Fogón” pasa a fundar la cooperativa "Mi Rancho", a partir de aquí Tomacito pasa a llevar adelante todos sus ideales y construir un pueblo rural que subsistirá por sus propios medios, sin depender de la ciudad. Este plan no cumple con las expectativas del grupo, generando al mismo tiempo una deuda de los terrenos donados, yendo estos a remate. Aquí ocurre un suceso que marca un antes y un después para la historia de Cerro Pelado, los pobladores logran recuperar las hectáreas perdidas comparándolos nuevamente, con la ayuda económica de cada uno de los pobladores, notándose así el comienzo del cooperativismo llevado adelante por "Tomacito". 
Luego de recuperados los terrenos se conforma la Sociedad Fomento de Cerro Pelado, donde se construye el galpón comunitario donde hoy se encuentra en el centro del pueblito, alrededor de este se fueron conformando las demás instituciones, Escuela, liceo, policlínica, comisaría, MEVIR (Comisión Honoraria Pro Erradicación de la Vivienda Rural Insalubre). Se puede destacar que además de Tomás Berrutti existió un grupo humano que lo acompañó en la fundación de este pueblo, que algunos de ellos aún hoy continúan con su legado siendo de esta forma los pilares de esta sociedad.

Hoy "Tomacito Berrutti” es considerado por la población de Cerro Pelado como el líder en la fundación de esta comunidad, por sus principios de Cooperativismo, hermandad, en busca de derechos y servicios fundamentales para el desarrollo de la comunidad rural. A su vez se generó una historia y un sentido de pertenencia que se percibe en las distintas actividades y tradiciones que se continúan reivindicando en la comunidad hasta hoy en día, se puede citar aquí a uno de los fundadores cuando hace referencia a la comunidad.“(...) por algo nos felicitaban y nos decían que Cerro Pelado era una institución ya de tantas cosas que habíamos conseguido y que iban a seguir consiguiendo las cosas porque había algo construido" (Entrevistado: L.P,2017).

Como ya se hizo mención anteriormente, se seleccionan dentro de las festividades dos que son tradicionales de la comunidad y que han perdurado en el tiempo, desde la fundación hasta los días de hoy. Estas son: fiesta del 25 de agosto: "Declaratoria de la independencia de la Provincia Oriental" y la fiesta de la comunidad los 29 de septiembre de cada año. Luego otra celebración de gran relevancia para esta población es la fiesta de la tradición, que surge con el director del liceo comunitario, Pedro Riera.

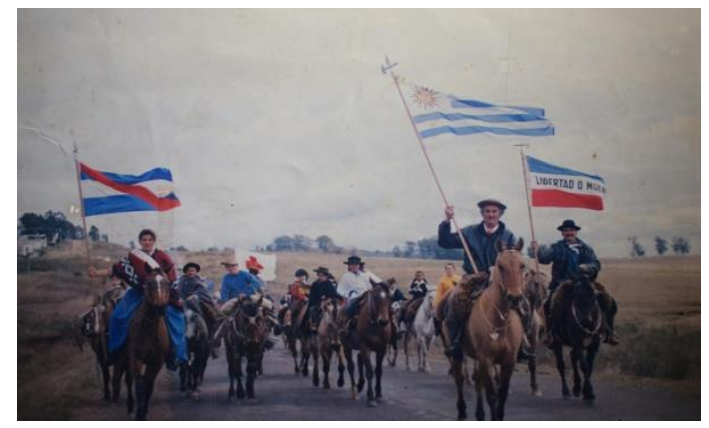

Fotografía (1) Fiesta del 25 de agosto: "Declaratoria de la Independencia de la Provincia Oriental”, Fuente: Propiedad Ramón Iglesias, 2017 


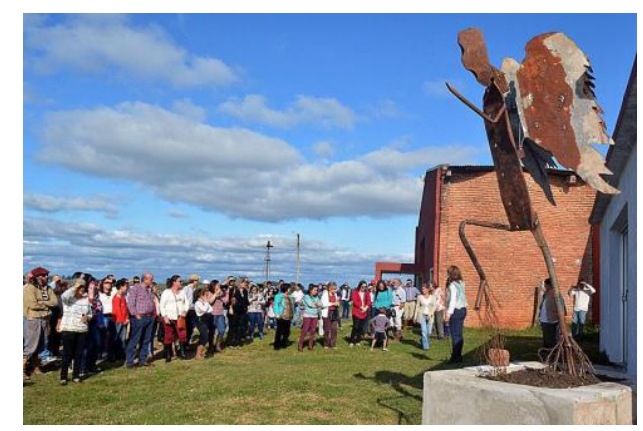

Fotografía (2) Fiesta de la comunidad 29 de septiembre, Fuente: Archivo Chasque FM, 2017, https://www.facebook.com/ELCHASQUE/photos/a.10155837580247164/10155837580902164/?type=3\&theater

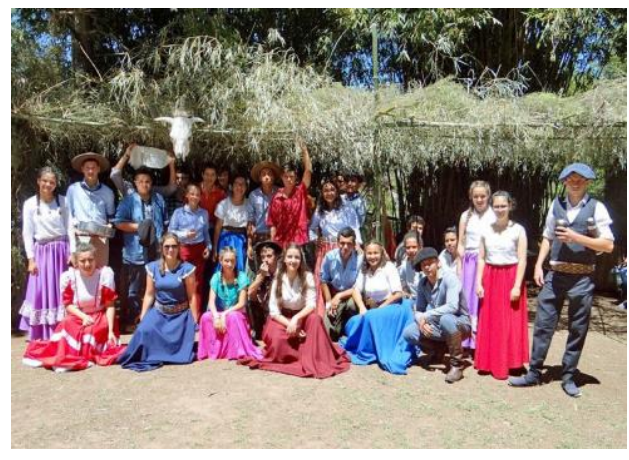

Fotografía (3) Fiesta de la tradición, Fuente: El Chasque FM, 2018,

https://www.facebook.com/ELCHASQUE/photos/a.10156881145422164/10156881148182164/?type=3\&theater

Las fotografías expuestas dejan constancia de las tres festividades que son relevantes para la comunidad ya que mediante estas muestran la esencia del pueblo y de las tradiciones que son típicas del interior de Uruguay, y la zona fronteriza Uruguay -Brasil, mejor dicho, de las zonas rurales, que cada vez hoy en día debido a la urbanización, globalización, tienden a ir perdiéndose en el tiempo.

La imagen número uno deja en evidencia lo que significa para la población de Uruguay y mucho más para las zonas rurales, que reivindican la fecha como un día que no se puede olvidar, sino que todo lo contrario, debe de permanecer y perdurar en la memoria nacional. Pero aún más permanece en la memoria colectiva de las distintas poblaciones, como por ejemplo la población de Cerro Pelado que asocia estas festividades patrias con las tradiciones e identidad propias de su pueblo. Una tradición que permanece y la población hacen énfasis en que permanezca, como así lo sostiene Halbwachs (s/f). “(...) retiene del pasado sólo lo que aún está vivo o es capaz de vivir en la conciencia del grupo que la mantiene. Por definición, no excede los límites de ese grupo." (HALBWACHS, (s/f), p.213-214).

En lo que respecta a las otras dos fotografías, el día de la comunidad y el día de la tradición es importante decir que son conjuntamente con la otra festividad una manera 
de reivindicar y mantener viva la identidad del poblado. Estas celebraciones funcionan como una herramienta encargada de transmitir la historia para generar un sentido de identidad que perdure de generación en generación. A través de las festividades esta historia se vivifica, se hace real en la memoria colectiva de la población.

(...) lo que persiste son imágenes totalmente confirmadas en alguna galería subterránea de nuestro pensamiento, sino, en la sociedad, todas las indicaciones necesarias para reconstruir esas partes de nuestro pasado que concebimos de forma incompleta o indistinta (...). (HALBWACHS, (s/f), p.210).

La fiesta de la tradición ha sido y es desarrollada por el liceo comunitario, en su origen con Pedro Riera, el director del Liceo, se desarrollaba un día en el mes, en el cual los estudiantes estaban en su libertada de usar sus vestimentas tradicionales, Bombacha de campo, camisa, y toda las pilchas que de tradición se utiliza en el medio rural. Pilchas Bouton (2014) define como “(...) llama el gaucho a las prendas de vestir, pero también a las de uso del recado, cuando son buenas o de valor." (BOUTON, 2014, p.69). Podemos entender esta celebración como una forma de educar a los jóvenes a través de las tradiciones, dar valor a lo cotidiano y más esencial de la vida rural.

Esto a su vez se percibe en la fiesta de la comunidad, donde los organizadores le dan participación a los jóvenes. Esta participación es de gran relevancia, ya que de esta forma los jóvenes se familiarizan con el evento y con la importancia que él tiene para la comunidad, serán estos los que continuarán reviviendo la historia y generando sentido de pertenencia. A través de las diferentes exposiciones de sus trabajos, que muchas veces forman parte de la currícula escolar, trabajan en red con las diferentes instituciones que funcionan en la comunidad logrando trabajar en equipo y presentar productos que son preciados y valorados por la comunidad. Así se refiere la entrevistada (A.I) cuando sostiene que es importante seguir con las tradiciones, actividades, fiestas y todo aquello que tiene su nacimiento en los tiempos de sus fundadores

\footnotetext{
Eso siempre hay que seguir, yo quiero que siempre haya alguien, hijo de un fundador (...) que siga para que eso no se pierda, eso no se puede perder porque es en eso que nosotros nos basamos para que siga la comunidad como es, tal cual es. (...) de ellos. Ser humildes y aprender de ellos, para que siga, para que no se pierda, eso no se puede perder de manera ninguna. Y mis hijas ya saben cómo es, como es que funciona y tratamos de que sigan, que le pregunten al abuelo y así los otros para que no se pierda eso. (Entrevistado: A.I, 2017)
}

Además, siguiendo a lo que hace referencia Candau (2012) estos jóvenes cargarán con la memoria individual como la capacidad que poseemos todos los seres humanos, como 
también cargarán con una memoria que es mantenida por un colectivo, se mantienen aquellas costumbres y elementos que son elegidos para ser mantenidos en la memoria. Serán estas características elegidas por el colectivo y mostradas por ellos como lo que los va a caracterizar como sociedad o conjunto. "maneiras de comer, dançar ou caminhar que, ao se tomarem dominantes, majoritárias ou unânimes, serão consideradas como características da sociedade em questão" (CANDAU, 2012, p.24). Claramente esto que describe el autor está presente en la comunidad y principalmente en las fiestas, allí se puede observar las comidas que son tradicionales del medio rural, como el popular asado que se realiza en cada una de ellas, guiso carretero, poroto, entre otras tantas más.

Se puede también identificar a Cerro Pelado como un lugar antropológico, siguiendo este concepto desarrollado por Marc Augé (2000) la población ha establecido sus propias reglas de convivencia, poseen una historia fundacional que funciona como el eje de la identidad de esta población, hay un sentido de pertenencia con el espacio geográfico y con el imaginario colectivo que allí se construyó. Este territorio está socialmente marcado, hay una cultura localizada, que es parte de cada individuo que allí se establece. "El lugar antropológico, para ellos, es histórico en la exacta medida en que escapa a la historia como ciencia. Este lugar que han construido los antepasados" (AUGÉ, 2000, p.32).

Esta historia no solo es transmitida de los adultos a los más jóvenes, sino que también a la nueva población que allí busca radicarse. La población originaria que carga con el sentir comunitario busca a través de distintos medios integrar al extranjero al sentido de pertenencia.

(...) la identidad del grupo (los orígenes del grupo son a menudo diversos, pero es la identidad del lugar la que lo funda, lo reúne y lo une) y es lo que el grupo debe defender contra las amenazas externas e internas para que el lenguaje de la identidad conserve su sentido.

(AUGÉ, 2000, p.27).

Involucrar a los nuevos pobladores a esta historia es una estrategia para que no se pierda la esencia e identidad de la comunidad.

El sentido de pertenencia al cual hace mención indirectamente el autor, en la comunidad de Cerro Pelado es muy notoria, en cada una de los diálogos allí establecidos los pobladores tratan de que esa esencia sea percibida tanto por los visitantes (como lo fuimos nosotras durante un tiempo) como aquellos que llegan al poblado a radicarse en el pueblo. Por este motivo (A.I) lo describe de tal forma que deja en claro su sentido de pertenencia y sosteniendo un discurso que se basa en defender y demostrar cuáles son sus ideales arraigados.

(...) hay mucha gente que no es de acá, y eso se trata, de mostrarle a esa gente a veces como funciona esto (...) nosotros que hicimos estas casas... ¿Sabes cómo celamos esto? porque eso fue hecho por nosotros. Nos dieron, no teníamos casa. Nos dieron esto, yo no tenía casa. Y es todo ellos, todo ellos, por medio de los 
fundadores, iban surgiendo proyectos, ellos iban estudiando y entrando y queriendo participar (...) (Entrevistado: A.I, 2017).

Debido a lo anteriormente dicho por el entrevistado, es importante destacar lo que sostiene Jelin (2002) en lo que respecta a la memoria, los olvidos y recuerdos que permanecen en el pueblo, que en definitiva son lo que conforman el relato de la historia que se cuenta, donde la selección de acontecimientos es importante, es decir que ellos son los que eligen que transmitir y que no, resaltar los recuerdos son significativos, los otros quedarán en el olvido "Abordar la memoria involucra referirse a recuerdos y olvidos, narrativas y actos, silencios y gestos. Hay en juegos saberes, pero también hay emociones y hay también huecos y fracturas". (JELIN, 2002, p.17). En cuanto a los recuerdos para subsistir necesitan de grupos, de la familia, de grupos vecinales, ya que mediante ellos se mantiene viva las tradiciones y donde quienes son los encargados de la trasmisión de ellos son los mayores que viven tanto en el pasado como en el presente, así lo sostiene Hernández (2005).

Cuando se hace mención al olvido, es importante aclarar que si bien tienen una connotación negativa, muchas veces es necesario que existan para que la memoria pueda subsistir y así ir construyendo y reconstruyendo su propia historia, así lo sostiene Jelin (2002) "el olvido y el silencio ocupan un lugar central. Toda narrativa del pasado implica una selección. (...)Esto implica un primer tipo de olvido "necesario" para la sobrevivencia y del funcionamiento del sujeto individual y de los grupos y comunidades.”.(JELIN, 2002, p.29)

Por lo tanto se puede analizar de esta forma como Cerro Pelado es una comunidad que busca pervivir a través de un cierto conservadurismo, luchan día a día para que la esencia de su comunidad no caiga en el olvido. Este conservadurismo es portado por los pobladores de forma inconsciente, se puede identificar en sus formas de actuar, como se muestran frente a la sociedad. Pero no solo esta comunidad carga con este conservadurismo sino que además todos los poblados rurales del Uruguay están imbricados por este cierto conservadurismo que los identifica, con lo nacional y principalmente con la cultura gauchesca, "Igualmente se constatan estructuras conservadoras en los comportamientos cotidianos de la mayoría de los ciudadanos, las cuales, sin embargo, están sometidas a una transformación histórica (...)”. (VON BEYME, 1985, p.12)

Como refiere Von Beyme (1985) no quiere decir que esta comunidad no se haya abierto a los cambios del mundo, existe una transformación. Se puede ver allí como en lo social existen transformaciones, desde el compromiso de las personas, las responsabilidades, algunos valores, a lo largo del tiempo se perdieron algunas tradiciones y han surgido algunas 
otras, la mujer ha adquirido un nuevo protagonismo, como también existe una gran influencia de las tecnologías, y de lo rural ha habido una cierta urbanización.

Al mismo tiempo es importante decir que Cerro Pelado posee una identidad propia principalmente muy arraigada, pero no se encuentra aislada, sino que por lo contrario, a través las instituciones que funcionan en la comunidad, como el liceo, la escuela y la Fomento. Es importante destacar que la Fomento Comunidad de Cerro Pelado tiene interacción con los demás poblados rurales que se encuentran a sus alrededores, como Amarillo, Tres Puentes, La Puente, Moirones, Cerrillada, Paso Hospital.

Si bien la interacción entre las diferentes instituciones tienen un rol importante, donde más es notaria esta relación es en las festividades que son también una forma de interacción entre estas poblaciones, y en este contacto es donde las demás poblaciones se contagian, y comienza a identificarse en cierta parte con la comunidad de Cerro Pelado. Nuevamente haciendo mención a Marc Augé (2000) Cerro Pelado es un lugar antropológico, un espacio de interacción, del cual emerge una cultura, una forma de vida particular, reivindicando siempre su origen. La frontera de este territorio está demarcado por la identidad hacia él (Augé, 2000).

\footnotetext{
"En términos geométricos, se trata de la línea, de la intersección de líneas y del punto de intersección. (...) se podría hablar, por una parte, de itinerarios, de ejes o de caminos (...) trazados por los hombres; por otra parte, de encrucijadas y de lugares donde los hombres se cruzan, se encuentran y se reúnen (...) construidos por ciertos hombres y que definen a su vez un espacio y fronteras más allá de las cuales otros hombres se definen como otros con respecto a otros centros y otros espacios." (AUGÉ, 2000, p. 33).
}

Por otro lado como ejemplo de esta interacción y de establecer conexiones entre las diferentes poblaciones que existen en los poblados aledaños, se encuentra la fiesta de las quinceañeras. En lo que respecta a esta fiesta, la misma es una celebración que reúne a las jóvenes que cumplan 15 años al correr de cada año y no puedan realizar su fiesta, ya sea por motivos económicos u otros. Esta es un claro símbolo de unión, compañerismo y por sobre todo compromiso. El compromiso que asume la comunidad es muy importante, ya que la idea inicial fue del director del Liceo, Pedro Riera, y organizada por el Liceo comunitario, todos participan en la organización, desde conseguir los vestidos hasta la decoración.

Al presenciar una de las ediciones de este evento, se pudo percibir cómo es una festividad importante, comienzan muy temprano del día para que a la noche las protagonistas tengan su noche soñada junto a sus familiares y sus más allegados. Aquí es importante hacer hincapié ya que la participación de la familia es muy relevante, por este motivo en la celebración se viven momentos de suma emoción, que comparten con el público que muchas veces asiste a presenciar y disfrutar del momento. 
Además en la ocasión que pudimos asistir a dicha fiesta, en primer instancia entran las jóvenes, se establece un momento emotivo con sus familiares, bailan el vals tradicional y realizan el corte de la torta con un brindis. Luego del brindis se abre al público en general que quiera asistir al evento cobrando un bono a beneficio de la comisión fomento, quien organizaron la fiesta en el año 2018.

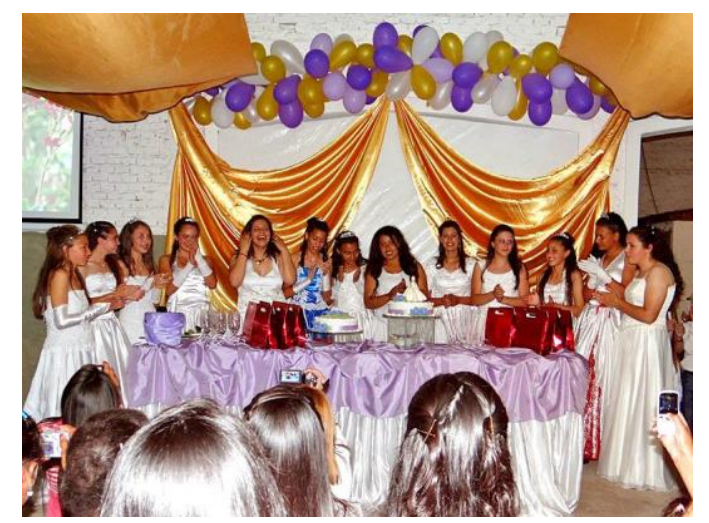

Fotografía (4) Fiesta de las quinceañeras, Fuente: El Chasque FM, 2013,

https://www.facebook.com/ELCHASQUE/photos/a.10151980159217164/10151980195802164/?type=3\&theater

Cabe destacar el papel que cumple la mujer en las festividades, y en la comunidad misma, se pudo percibir la notable función social, cultural, económico y político que desarrolla la mujer en la comunidad de Cerro Pelado. Por este motivo se creyó pertinente destacar dentro de dicho artículo el rol de mujer en el medio rural, en las actividades que realizan. En el ámbito político se puede subrayar que en la comisión fomento de la comunidad está mayoritariamente integrada por mujeres que llevan a cabo los diversos temas que ha esta comisión corresponden, desde la organización de las fiestas, otros beneficios, el proyecto de colonización, y demás actividades interinstitucionales con la escuela y el liceo comunitario.

En lo económico se puede señalar como un emprendimiento de la mujer rural de esta comunidad "Arte y Maña” un negocio de venta de artesanías, estas poseen un local en tal comunidad donde tienen a la venta diversos productos artesanales realizados por distintas mujeres, cada una aporta allí lo que sabe construir, producir. Allí se puede encontrar vestimentas en telas, lana, almohadones, carteras, joyería, objetos de decoración, productos comestibles como la miel.

Como actividades que realizan las mujeres está el trabajo doméstico, así lo expresan las entrevistas, cumplen el rol tradicional dentro de un modelo de familia patriarcal muy arraigado en las zonas rurales del Uruguay, principalmente a través de la violencia simbólica 
,como así lo llama Bourdieu (2000), en este modelo se encuentran presentes “(...) las relaciones de poder en las que están atrapadas, unos esquemas mentales que son el producto de la asimilación de estas relaciones de poder y que se explican en las oposiciones fundadoras del orden simbólico"(BOURDIEU, 2000, p. 27-28).

Esta visión se encuentra visible en esta comunidad, pero es necesario destacar el papel de productoras de estas mujeres y su aporte a la economía de la comunidad, por lo que se pudo percibir aquí una cierta autonomía de la mujer al ser una productora económica, ellas propusieron su propio negocio y lo mantienen a través de su trabajo. Poseen una administración propia que le genera ganancias a cada una de las productoras, a su vez la mayoría de estas productoras cuentan con especialización en lo que producen y se continúan perfeccionando. Tener un lugar para vender sus productos también sirve como un espacio donde se intercambian ideas y aprenden unas de otras.

Dos Santos y da Silva (2018) en una investigación en una comunidad rural en Río de Janeiro analizan la división sexual del trabajo, siguiendo este análisis en la comunidad de Cerro Pelado existe una división sexual del trabajo muy arraigado, los hombres se encargan de las actividades rurales y en comparación muy pocas mujeres lo hacen, trabajo que implica actividades con ganado vacuno, bovino, equino, y administrar grandes plantaciones.

\footnotetext{
"No espaço rural, a divisão sexual do trabalho e as relações de gênero são também antagônicas. (...) Isso se observa claramente na divisão do trabalho, onde é reservado aos homens a condução das atividades principais geradoras de renda e às mulheres a ajuda ao marido, o cuidado da família e da casa e das pequenas criações e cultivos. Essa organização social das famílias rurais perpetua a ideia do patriarcado." (DOS SANTOS; DA SILVA, 2018, p. 103).
}

La producción agropecuaria es la fuente económica fundamental de las comunidades rurales y en especial de Cerro Pelado, la misma es llevada a cabo principalmente por los hombre, y el trabajo realizado por las mujeres como lo analizan Dos Santos y da Silva (2018) es considerado como un acto afectivo hacia su familia. "Esse trabalho "invisível" efetuado para os membros da família, era considerado como algo natural, feito em nome do amor e dever maternal (HIRATA et al, 2000).” (DOS SANTOS; DA SILVA, 2018, p. 102). El trabajo femenino comúnmente considerado como un aporte a la economía familiar, una actividad menor colaborativa, así lo avala una entrevistada “(...) siempre algo uno aporta porque siempre algo se vende entonces ayuda también en la economía de la casa.” (Entrevistada: P.S, 2018).

El trabajo femenino ya sea doméstico o de otra índole es invisibilizado, desvalorizado en una sociedad que tiene como modelo el patriarcado. No solo por los hombres sino que está impregnado en el imaginario colectivo esta forma de tratar y visualizar la labor de la mujer. Esta concepción en una sociedad patriarcal se transporta a las relaciones sociales, a las 
relaciones amorosas, al habitus, a lo cultural, las formas de expresarse y de vivir, también, principalmente emerge en lo político, donde no coincide con este sistema, la figura de una mujer gobernante. Así lo analiza Bourdieu (2000) en su libro "A dominação masculina” el cual argumenta que la dominación comienza desde lo biológico y se desprende a todos los ámbitos de la vida de los seres humanos.

(...) la dominación masculina (...) se afirma en la objetividad de las estructuras sociales y de las actividades productivas y reproductivas, y se basa en una división sexual del trabajo de producción y de reproducción biológico y social que confiere al hombre la mejor parte, así como en los esquemas inmanentes a todos los hábitos. (BOURDIEU, 2000, p.27)

Si bien existe esta división sexual del trabajo aún muy arraigado en esta comunidad, como una característica del modelo de familia patriarcal, la mujer en esta comunidad posee y se ha ganado un espacio muy importante, haciendo constantemente uso de él en todos los ámbitos, y principalmente cambiando la rutina o actividades que estaban acostumbradas a realizar, así lo manifiesta una de las entrevistadas, "Sí, nos cambió. A mí por lo menos me cambio porque yo por ejemplo ahora ya no tengo más los hijos en casa y todo, ya tengo un motivo que salgo, que me reúno con las vecinas acá, que salimos a las ferias, para mi es bueno eso.” (Entrevistada: M.V, 2018). Además, según nuestra interpretación, (M.V) deja entrever en su diálogo que es importante que la mujer logre tener estos espacios, ya que mediantes ellos puede socializar, compartir actividades que son importantes para el crecimiento de cada una de ellas.

El emprendimiento "Arte y Maña" siempre está presente en todas las festividades de la comunidad, en diferentes modalidades, ya sea en su local, o sus productoras instalan un estante con los productos a la venta y también han participado en las festividades mostrando un desfile femenino con las diferentes prendas de vestir, desfilan mujeres mayores, adolescentes y niñas. En estas instancias, los desfiles tienen el propósito de venta de los productos pero también es parte de un entretenimiento para el público, contribuyendo también a generar un mayor valor a el trabajo de estas emprendedoras.

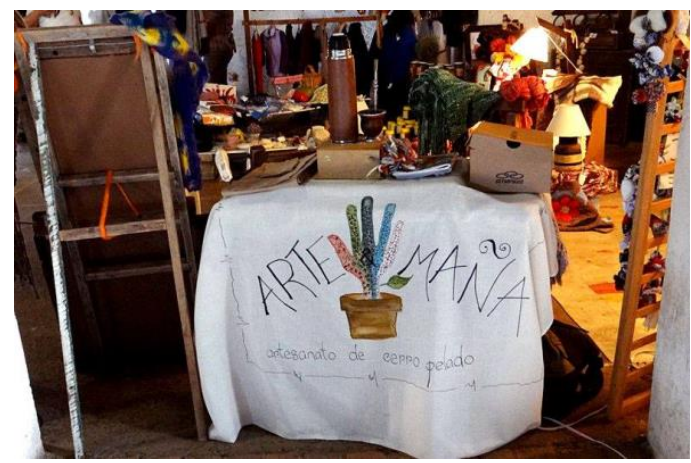

Fotografía (5) Grupo de artesanas de la comunidad de Cerro Pelado: “Arte y Mania”, 


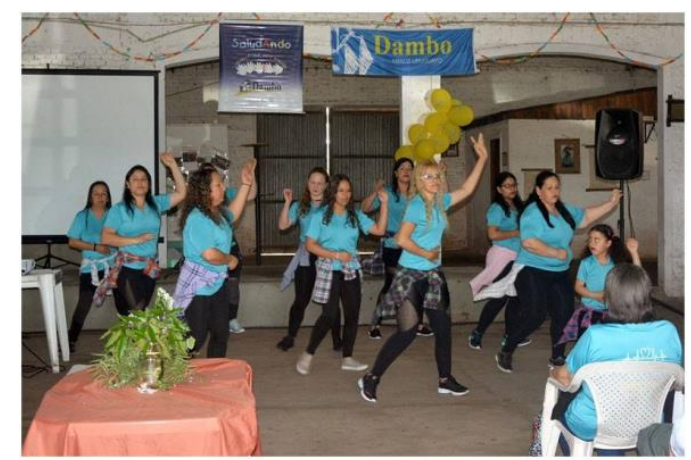

Fotografía (6) Grupo de Zumba: Fuentes: El Chasque FM, (2018)

https://www.facebook.com/ELCHASQUE/photos/a.10156773206972164/10156773213532164/?type=3\&theater

En cuanto al rol de la mujer en lo social se puede destacar el grupo de Zumba. Este grupo surge como iniciativa de las mujeres de la comunidad hace un tiempo atrás, ya que ven a en esta actividad una oportunidad para salir de la rutina, cuidar su salud y al mismo tiempo establecer relaciones sociales con las demás comunidades, instituciones desde otro ámbito, pero aún más entre ellas.

El grupo Zumba a lo largo del tiempo se fue fortaleciendo y hoy es reconocido por toda la comunidad como un conjunto donde la mujer tiene otro papel, sirve como tiempo de recreación donde comparten alegría, diversión y compromiso. El compromiso está presente en cada evento en el cual presentan sus coreografías porque en ellas está presente una organización para presentar un buen trabajo.

Por otro lado es importante destacar que las mujeres que forman parte de este grupo realizan otras actividades para sustentarse por sí mismas, por eso realizan beneficios para recaudar el dinero necesario que será luego destinado en lo que sea necesario para el grupo, ya sea ropa para bailar, colchonetas, para viajar a concursos y otras necesidades que necesita solventar este grupo.

El grupo zumba es el claro ejemplo de que la mujer tiene un papel importante en dicha comunidad porque su lugar de ensayo es la institución más importante de la comunidad, el galpón “Tomacito Berrutti”. Durante la semana el grupo de zumba tiene la llave del local para realizar sus ensayos y actividades, los ensayos son tres días a la semana durante una hora.

Desde lo cultural, que es en lo que se centra este trabajo, el papel de la mujer es notorio y activo ya que la participación de cada una de ellas hoy se destaca, aquí es importante decir 
que en la fundación de Cerro Pelado la mujer tenía un papel más pasivo, participaba pero desde lo que era permitido o lo que iba con su género socialmente construido, hoy eso cambió en la comunidad. La mujer hoy dentro de la comunidad ha ganado un nuevo espacio, hoy son ellas mayoritariamente quienes organizan las fiestas, una de las causas puede ser por su participación y activo labor en la Fomento Comunidad de Cerro Pelado.

Como ya se dijo anteriormente, la comunidad de Cerro Pelado ha utilizado a las fiestas como una herramienta para promover y generar identidad, y las principales organizadoras y promotoras de estas festividades es la mujer, principalmente porque la institución que organiza las festividades es la comisión fomento y esta está integrada mayoritariamente por mujeres. Por tanto son ellas quienes impulsan y generan iniciativa para que se realicen las fiestas tradicionales y son las promotoras de que la historia de la fundación y de sus fundadores permanezca en la memoria colectiva de esta comunidad.

Los recuerdos que permanecen en la memoria se conforman de objetos, imágenes, relatos, que son transmitidos hacia las nuevas generaciones, así lo sostiene Pierre Nora (2008)

La memoria es la vida, siempre encarnada por grupos vivientes y, en ese sentido, está en evolución permanente, abierta a la dialéctica del recuerdo y de la amnesia, inconsciente de sus deformaciones sucesivas, vulnerable a todas las utilizaciones y

Manipulaciones. ( PIERRE NORA, 2008, p.21).

En relación con lo anterior la mujer es una gran protagonista de este grupo viviente y contribuye a esa dialéctica del recuerdo transmitiendo a través de las distintas celebraciones la identidad y el sentido de pertenencia hacia sus hijos y todos aquellos que pertenezcan a la nueva generación, por tanto la mujer y la comunidad funcionan como actores transmisores de cultura.

\section{Conclusión}

Para finalizar el trabajo investigativo es importante puntualizar que mediante las festividades la comunidad ha logrado construir, reconstruir y perdurar sus tradiciones haciendo que sus habitantes se identifiquen con el lugar y que lo elijan día a día, es decir que cada actividad que se realice dentro de dicho poblado (ya sea relacionadas a las festividades o no) genere un fuerte interés en participar por parte de la comunidad, desde su organización, pasando por el proceso hasta concretarse.

Haciendo referencia a el proceso y la organización de las fiestas en la comunidad de Cerro Pelado, los entrevistados remarcan que en un comienzo la organización de estos eventos implicaba sacrificios de toda la población, era realizada con labor y pasión por el poblado en 
que conviven. La organización implicaba muchos días de preparación y dedicación de los habitantes y los que allí guiaban en un principio fueron los fundadores, que además de ser una instancia de trabajo se volvía un momento para aprender de los que tenían más edad y habían dirigido la fundación de ese pueblo.

Las festividades son un proceso, implican más que solo el día del festejo, es una instancia de aprendizaje y de enseñanza, de fortalecer valores, de hacer más fuerte el sentido de pertenencia, que se transmiten en esta comunidad a través de las personas, del relato oral, documentado pero también desde las instituciones que allí persisten. Estas instituciones tienen un alto valor simbólico pero principalmente emocional, en este caso es importante citar a Pierre Nora (2008) desde el lugar que ocupa la memoria en estos temas, de recuerdos, emociones y aprendizajes, él sostiene que:

Fin de las sociedades-memorias, como todas las que aseguraban la conservación y trasmisión de valores, iglesia o escuela, familia o Estado. Fin de las ideologíasmemorias, como todas las que aseguraban el pasaje regular del pasado al provenir o indican, desde el pasado, lo que había que retener para preparar el futuro. (PIERRE NORA,2008, p.20).

Los entrevistados también destacan que hoy la mayoría de las cosas han cambiado, a consecuencia de que el mundo así lo ha hecho, las festividades ya no pasan por el mismo proceso, expresan preocupación, el grupo destaca que la población no le dedica tiempo necesario o el que es pertinente según ellos, para la elaboración de las festividades u otras actividades relacionadas a las necesidades de esta comunidad.

A pesar de esta nueva realidad los pobladores de Cerro Pelado, unos pocos hoy buscan a través de toda su entrega seguir con sus tradiciones, continuar con sus fiestas, y principalmente buscar espacios para hacer más fuertes los valores de cooperativismo y de comunidad, insisten en que esto no se pierda y que continúe viva perdurando en la memoria y en la historia del lugar. Se puede analizar de esta forma como Cerro Pelado es una comunidad que carga con cierto conservadurismo, trabajan directa e indirectamente día a día para que la esencia de su comunidad no caiga en el olvido; si bien como se menciona en el trabajo esta comunidad ha ido transformándose, principalmente en lo social.

Por lo tanto para lo anteriormente dicho lo que han tomado como herramienta es en cada año homenajear a alguien de la comunidad que ha portado con los mejores valores, intenciones y ha prestado su mayor labor a la comunidad, principios que son heredados de los primeros fundadores. Este homenaje se realiza el día de la comunidad ( 29 de setiembre) y se lleva a cabo en el galpón, lugar que identifica a la comunidad con sus raíces, 
claramente se puede identificar que por el tiempo pasa pero los recuerdos y tradiciones perduran.

Además, como punto a destacar en esta comunidad siempre se reconoce a través de diferentes medios ya sean en fiestas tradicionales como en aquellas que no lo son tanto, a las personas que conservan, continúan y dan a conocer con orgullo su comunidad, el lugar que con tanto sacrificio construyeron.

Para finalizar el artículo, es pertinente que destaquemos a la mujer dentro de la comunidad, adentrarnos en la actualidad, en los temas que son en el siglo XXI está en mesa de discusión y que de tal forma debemos de poco a poco ir interiorizándonos con ellos para convivir en un mundo que continuamente está cambiando. Por este motivo es pertinente que se destaque el papel que tiene la mujer en la comunidad de Cerro Pelado, que no es reciente, sino que todo lo contrario, ya se venía gestando hace mucho tiempo atrás.

Por lo tanto fue y es necesario retomar el enfoque que se tuvo en la investigación hacia el papel que tiene la mujer en la comunidad de Cerro Pelado. Hacer hincapié en que ellas demuestran explícitamente su autonomía a través de los emprendimientos que han desarrollado, tanto sociales y económicos. Pero también es muy importante posicionar a la mujer como una agente que promueve cultura e identidad, por ser quienes mayoritariamente dirigen, organizan y promueven las actividades culturales de la comunidad, donde se encuentran las fiestas.

\section{Referencias}

BOURDIEU, P. “A dominação masculina”, Barcelona, ANAGRAMA, 2000, Disponible en: http://www.nomasviolenciacontramujeres.cl/wp-content/uploads/2015/09/Bondiu-Pierre-ladominacion-masculina.pdf

DOS SANTOS SILVA, M.; DA SILVA, A. "La división sexual del trabajo en el asentamiento Zumbi de los Palmares en campos de los Goytacazes (RJ)", Tessituras, Pelota, v.6.n.6 ,p.10-121, jan./jun. $2018 . \quad$ Disponible en: https://periodicos.ufpel.edu.br/ojs2/index.php/tessituras/article/view/12582/9002

JELIM, E.; “Los trabajos de la memoria”, ed. Siglo veintiuno, Madrid, España, 2002.

HALBWACHS. M. "Memoria colectiva", Traducido por Amparo LASÉN DÍAZ. S/F, Disponible en:

http://ih-vm-cisreis.c.mad.interhost.com/REIS/PDF/REIS_069_12.pdf

HERNÁNDEZ RAMIREZ, V. "Reseña de La memoria colectiva de Maurice Halbwachs”, Revista de Pensamiento e Investigación Social, Universidad Autónoma de Barcelona, España, Núm 7, 2005 
VON BEYME. K. “El conservadurismo”, Revista de Estudios Políticos (Nueva Época) Número 43, 1985.

BOUTON, R. "La vida rural en el Uruguay ", Banda Oriental; Montevideo, 2014.

CANDAU, J. “Memória e identidade”, Editora Contexto,2012

AUGÉ, M. “Los no lugares”, Espacios del anonimato. Barcelona, Gedisa, 2000.

\subsection{Entrevistados}

Entrevista a L.P

Entrevista a A.I

Entrevista P.S

Entrevista M.V

\subsection{Fotografías}

Fotografía (1): Fiesta del 25 de agosto: "Declaratoria de la Independencia de la Provincia Oriental”, Fuente: Propiedad Ramón Iglesias, 2017

Fotografía (2): Fiesta de la comunidad 29 de septiembre, Fuente: Archivo Chasque FM, 2017, https://www.facebook.com/ELCHASQUE/photos/a.10155837580247164/10155837580902 $\underline{164 / ? \text { type }=3 \& \text { theater }}$

Fotografía (3): Fiesta de la tradición, Fuente: El Chasque FM, 2018, https://www.facebook.com/ELCHASQUE/photos/a.10156881145422164/10156881148182 $164 /$ ?type $=3 \&$ theater

Fotografía (4): Fiesta de las quinceañeras, Fuente: El Chasque FM, 2013, https://www.facebook.com/ELCHASQUE/photos/a.10151980159217164/10151980195802 $164 /$ ?type $=3 \&$ theater

Fotografía (5): Grupo de artesanas de la comunidad de Cerro Pelado: “Arte y Mania”, Fuentes: El Chasque FM (2016)

https://www.facebook.com/ELCHASQUE/photos/a.10154750950202164/10154750952382 $\underline{164 / \text { type }=3 \& \text { theater }}$

Fotografía (6): Grupo de Zumba: Fuentes: El Chasque FM, (2018) https://www.facebook.com/ELCHASQUE/photos/a.10156773206972164/10156773213532 $164 /$ type $=3 \&$ theater 